\title{
Nickel-Catalyzed Cross-Electrophile Coupling of the Difluoro- methyl Group for Fluorinated Cyclopropane Synthesis
}

\author{
Erika L. Lucas ${ }^{1}$ \\ Tristan M. McGinnis \\ Anthony J. Castro ${ }^{2}$ (i) \\ Elizabeth R. Jarvo*(i)
}

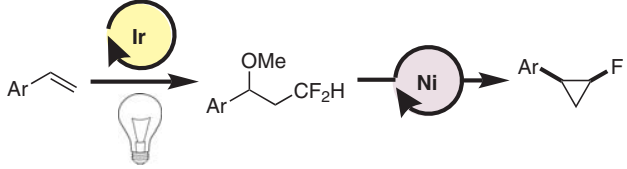

Department of Chemistry, University of California-Irvine,

4114 Natural Sciences I, Irvine, CA 92697-2925, USA

erjarvo@uci.edu

Published as part of the Cluster

Modern Nickel-Catalyzed Reactions
Received: 29.07.2020

Accepted after revision: 30.12 .2020

Published online: 28.01 .2021

DOI: 10.1055/s-0040-1706013; Art ID: st-2020-k0418-c

Abstract Herein, we report a new strategy for fluorinated cyclopropane synthesis. Photocatalytic olefin difluoromethylation is coupled with a nickel-catalyzed intramolecular cross-electrophile coupling (XEC) reaction between a difluoromethyl moiety and a benzylic ether. To the best of our knowledge, this is the first example of a XEC reaction employing a difluoromethyl group as an electrophile. A plausible mechanism is highlighted, and DFT calculations are included to support the observed stereochemical outcome.

Key words nickel, cross-electrophile coupling, fluorinated cyclopropane, difluoromethyl

Both cyclopropanes and fluorine atoms are frequently employed in medicinal chemistry to modify chemical, physical, and biological properties of drug candidates. ${ }^{3}$ Fluorinated cyclopropanes are gaining attention as relevant building blocks in pharmaceutical design, as they combine the unique chemical and structural features of the two in- dependent functional groups. For example, these moieties are present in medicinal agents bearing activity against several different indications, including depression, cancer, and bacterial infections (Scheme 1a). ${ }^{3-5}$ In the design of Zosuquidar, the fluorocyclopropane motif was installed to improve oral bioavailability by increasing chemical stability under acidic conditions. ${ }^{5}$

Due to the utility of fluorinated cyclopropanes in drug design, methods for the synthesis of these moieties are beginning to be developed (Scheme 1b). ${ }^{3}$ Two prominent approaches include addition of carbenes to fluoroalkenes and addition of fluorocarbenes to alkenes, both of which employ highly reactive diazo compounds or carbenoid equivalents. ${ }^{3,6}$ We envisioned a new strategy that would couple emerging methods in introduction of difluoromethyl groups $^{7}$ with an intramolecular cross-electrophile coupling (XEC) reaction (Scheme 1c). Building upon our laboratory's previously reported nickel-catalyzed XEC reaction of alkyl fluorides for cyclopropane synthesis, we conceived that a difluoromethyl group could be employed as an electrophile

(a) Fluorinated cyclopropanes in pharmaceuticals
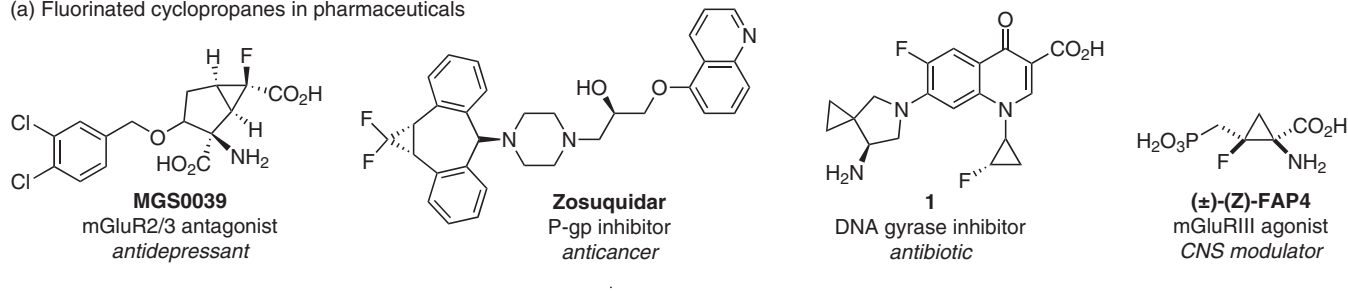

(b) Traditional synthesis of fluorinated cyclopropanes
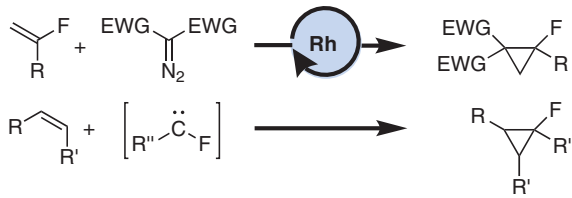

(c) Our approach

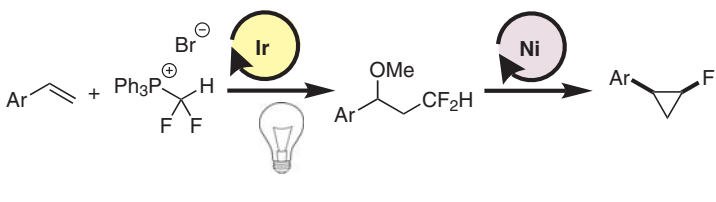

Scheme 1 Synthesis and applications of fluorinated cyclopropanes 
in a related XEC reaction for fluorinated cyclopropane synthesis. ${ }^{8}$ The notion of engaging the carbon-fluorine bond of a difluoromethyl group in a XEC reaction presents a notable challenge: the strength of the $\mathrm{C}-\mathrm{F}$ bond increases with each additional fluorine atom attached to the central carbon atom due to increased electrostatic forces. ${ }^{9}$ This work describes a new approach for fluorinated cyclopropane synthesis, wherein the photocatalytic difluoromethylation of olefins is paired with a nickel-catalyzed intramolecular XEC reaction between benzylic ethers and difluoromethyl groups. Furthermore, the basis for the stereochemical outcome and a proposed mechanism of the XEC reaction are highlighted.

Owing to the importance of fluorinated compounds in drug development, chemists have spent the past several decades designing creative approaches for the introduction of fluorine atoms and fluorine-containing moieties into organic molecules. ${ }^{10}$ While fluorination and trifluoromethylation reactions are well-established, the analogous difluoromethylation transformations remain a relatively nascent area of research. One contemporary approach for the efficient introduction of difluoromethyl groups is the radical difluoromethylation of olefins. ${ }^{7}$ A variety of difluoromethyl radical precursors have been designed, influenced by related trifluoromethylation reagents such as Umemoto's reagent and Langlois' reagent., ${ }^{70}$ In these radical difluoromethylation reactions, the carbon-centered radical resulting from difluoromethyl addition can undergo diverse transformations, including hydroxylation, ${ }^{11}$ etherification, ${ }^{12}$ amination, ${ }^{13}$ halogenation, ${ }^{14}$ carboxylation, ${ }^{15}$ arylation, ${ }^{16}$ alkylation, ${ }^{17}$ cyanation, ${ }^{18}$ and hydrogenation. ${ }^{19,20}$

We employed the Qing laboratory's oxydifluoromethylation procedure to synthesize benzylic alcohol 4 as a key intermediate for the synthesis of benzylic ether, thioether, and ester substrates for the nickel-catalyzed XEC reaction (Scheme 2a). ${ }^{11 a}$ This synthetic route enables the efficient installation of both the benzylic $\mathrm{C}-\mathrm{O}$ bond and the difluoromethyl group from commercially available 2-vinylnapthalene (2). Phosphonium salt $\mathbf{3}$ was generated in a straightforward three-step procedure from inexpensive starting materials. ${ }^{21,22}$ Although $\mathrm{fac} \operatorname{Ir}(\mathrm{ppy})_{3}$ is commercially available,

(a) Oxydifluoromethylation reaction for synthesis of benzylic alcohol 4 (ref. 11a)

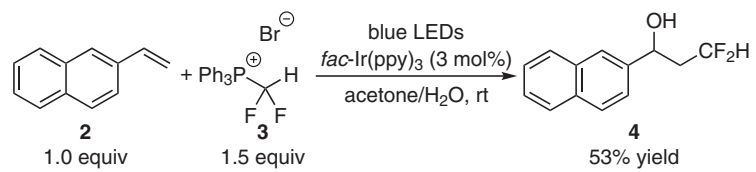

(b) Oxydifluoromethylation reaction for synthesis of benzylic ether $\mathbf{5}$ (ref. 11a)

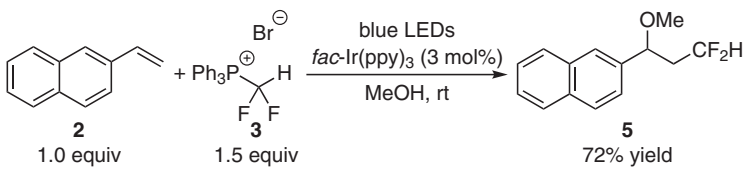

Scheme 2 Substrate synthesis the iridium catalyst could also be easily accessed in two steps from iridium(III) chloride hydrate. ${ }^{23}$ Additionally, we synthesized benzylic ether $\mathbf{5}$ in a single step by replacing the $\mathrm{H}_{2} \mathrm{O}$ /acetone solvent with $\mathrm{MeOH}$ in the oxydifluoromethylation reaction to trap the intermediate carbocation (Scheme 2b).

We began our evaluation of the nickel-catalyzed XEC reaction for fluorinated cyclopropane synthesis by assessing the efficacy of various benzylic electrophiles (Scheme 3). In related cross-coupling (XC) and XEC reactions of benzylic ethers, Lewis acidic $\mathrm{Mg}$ (II) species have played an important role in facilitating the initial oxidative addition of the C$\mathrm{O}$ bond. ${ }^{24}$ Specifically, $\mathrm{MgI}_{2}$, which is present in methylmagnesium iodide solutions due to the Schlenk equilibrium, has been identified as an important component of these XC and XEC reactions. ${ }^{25}$ Accordingly, we designed a range of substrates containing pendant Lewis basic heteroatoms that could promote the binding of Lewis acidic $\mathrm{MgI}_{2}$, and in turn facilitate oxidative addition of the benzylic electrophile. ${ }^{26}$ Unfortunately, substrates $\mathbf{7}$ and $\mathbf{8}$ bearing pendant pyridine functionalities did not afford fluorinated cyclopropane cis6 when subjected to the reaction conditions. Benzylic ester 9 containing a pendant thioether moiety was also unable to generate the desired cyclopropane product. We next hypothesized that commonly utilized electrophiles such as pivalates and tosylates could improve the results, but 10 and $\mathbf{1 1}$ did not produce cyclopropane cis-6. Finally, we were pleased to observe that thioether $\mathbf{1 2}$ engaged in the desired $\mathrm{XEC}$ reaction, albeit in low yield and with poor diastereoselectivity. We aimed to improve the yield of the XEC reaction by designing a substrate containing a 2-methoxyethylether appendage, which has previously been employed as a traceless directing group for related Ni-catalyzed Kumada XC reactions. ${ }^{26}$ We were delighted to observe that substrate 13 afforded the desired product in $22 \%$ yield and 3:1 dr. Ultimately, we found that simple methyl ether $\mathbf{5}$, without any

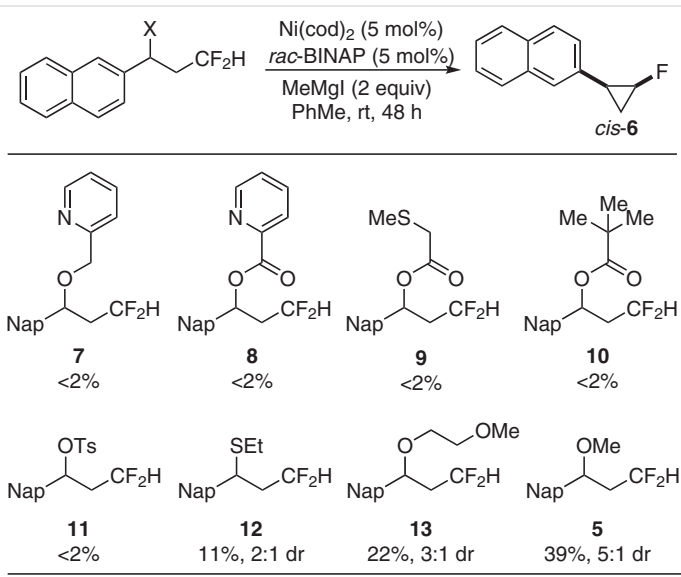

Scheme 3 Optimization of the benzylic electrophile. Yield is determined by ${ }^{1} \mathrm{H}$ NMR spectroscopy based on comparison to PhTMS as internal standard. 
pendant Lewis basic functionalities, afforded the best results, generating fluorinated cyclopropane cis-6 in 39\% yield and 5:1 dr. At this point, we concluded that methyl ethers are adequate benzylic electrophiles for this transformation and proceeded to evaluate the other key components of the XEC reaction.
After identifying methyl ethers as optimal benzylic leaving groups, we next evaluated reductants (Table 1). First, we hypothesized that methylmagnesium iodide could be replaced with alternative alkylmetal reagents. Unfortunately, $\mathrm{AlMe}_{3}$ and $\mathrm{ZnEt}_{2}$ did not yield fluorinated cyclopropane $\mathbf{6}$ when employed in the XEC reaction (entries 2 and 3). Moving forward, we were inspired by the Gong group's application of $\mathrm{B}_{2} \mathrm{Pin}_{2}$ as a reductant in nickel-catalyzed alkyl-alkyl
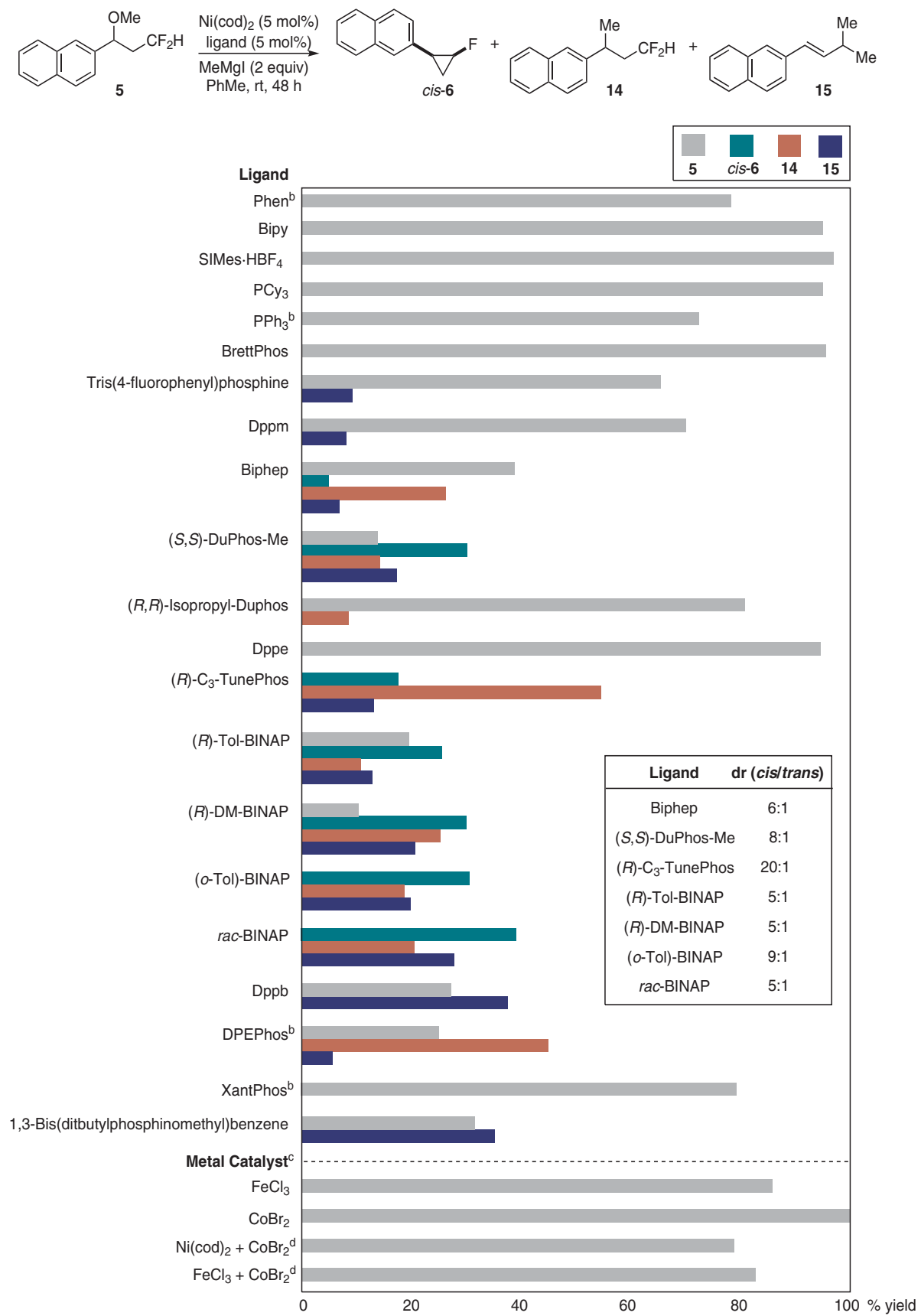

Scheme 4 Evaluation of ligands and transition-metal catalysts. ${ }^{a}$ Yield determined by ${ }^{1} \mathrm{H}$ NMR based on comparison to PhTMS as internal standard. ${ }^{\mathrm{b}}$ Reaction was run for $24 \mathrm{~h}$. ${ }^{c}$ Ligand $=$ rac-BINAP. ${ }^{\mathrm{d}} 5 \mathrm{~mol} \%$ of each catalyst were used. 
Table 1 Evaluation of Reductants

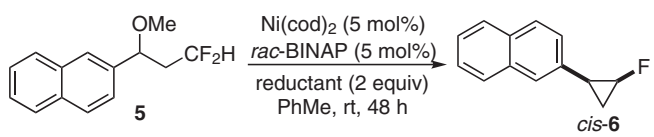

\begin{tabular}{llcl}
\hline Entry & Reductant & cis-6 (\%) & dr (cis/trans) \\
\hline 1 & MeMgl & 39 & $5: 1$ \\
2 & $\mathrm{AlMe}_{3}$ & $<2$ & - \\
3 & $\mathrm{ZnEt}_{2}$ & $<2$ & - \\
4 & $\mathrm{~B}_{2} \mathrm{Pin}_{2}$ & $<2$ & - \\
\hline
\end{tabular}

${ }^{a}$ Yield determined by ${ }^{1} \mathrm{H}$ NMR spectroscopy based on comparison to PhTMS as internal standard.

XEC reactions. ${ }^{27}$ However, when utilized in our nickel-catalyzed XEC reaction, $\mathrm{B}_{2} \mathrm{Pin}_{2}$ did not afford the desired cyclopropane product (entry 4 ). Based on these observations, the distinct reactivity of methylmagnesium iodide is key for the success of the XEC reaction.

With the optimal leaving group and reductant identified, we decided to evaluate different ligands (Scheme 4). First, we found that nitrogen-based ligands and NHC ligands only afforded recovered starting material, with no generation of cis-6. We next evaluated a series of monodentate phosphine ligands. Although $\mathrm{PCy}_{3}, \mathrm{PPh}_{3}$, and BrettPhos resulted solely in starting material, tris-(4-fluorophenyl)phosphine generated $8 \%$ of olefin byproduct 15 . Presumably, $\mathbf{1 5}$ is formed via oxidative addition of the nickel catalyst to the benzylic ether, $\beta$-hydride elimination, and then Kumada cross-coupling between the resulting allylic $\mathrm{C}-\mathrm{F}$ bonds and methylmagnesium iodide. After observing some reactivity with a monodentate phosphine ligand, we transitioned to bidentate phosphine ligands. Although dppe and Xantphos afforded only recovered starting material, dppm, $(R, R)$-isopropyl-Duphos, dppb, DPEPhos, and 1,3bis(di-tert-butylphosphinomethyl)benzene all generated at least one identifiable byproduct. Along with previously observed olefin 15, byproduct 14 was also seen as a result of competitive Kumada cross-coupling between benzylic ether $\mathbf{5}$ and methylmagnesium iodide. Finally, we found that biphep, $(R)$ - $C_{3}$-Tunephos, $(R)$-Tol-BINAP, $(S, S)$-Duphos$\mathrm{Me},(R)$-DM-BINAP, $\boldsymbol{o}$-Tol-BINAP, and rac-BINAP all afforded cis-6. $(R)-\mathrm{C}_{3}$-Tunephos generated the fluorinated cyclopropane product in $20: 1 \mathrm{dr}$, albeit in only $17 \%$ yield. Overall, rac-BINAP remained the optimal choice of ligand due to the superior yield and good diastereoselectivity.

We next evaluated alternative transition-metal catalysts. Because iron and cobalt complexes have been widely successful catalysts for cross-electrophile coupling reactions, we selected $\mathrm{FeCl}_{3}$ and $\mathrm{CoBr}_{2}$ as potential catalysts (Scheme 4). ${ }^{28}$ Unfortunately, XEC reactions employing these iron and cobalt catalysts did not afford any fluorinated cyclopropane cis-6, and instead resulted in recovered starting material. Additionally, $\mathrm{CoBr}_{2}$ in combination with $\mathrm{Ni}(\mathrm{cod})_{2}$ or $\mathrm{FeCl}_{3}$ did not yield the desired cyclopropane product. We concluded that $\mathrm{Ni}(\operatorname{cod})_{2}$ is the optimal catalyst for the intramolecular XEC reaction.

Alternative substrates bearing aryl substituents, also reacted to provide the desired fluorocyclopropanes in modest yields (Scheme 5). As anticipated based on our prior work, naphthylic or heterocyclic substituents were sufficient in activating the benzylic position. In related XEC reactions, we have determined that benzylic sulfonamides react similarly to benzylic ethers. ${ }^{29}$ This is the case for the XEC to form fluorinated cyclopropanes as well. For example, generation of $\mathbf{6}$ from the corresponding ether or sulfonamide provides similar yield and diastereoselectivity, and cyclopropanes 16 and 17 could be prepared from the corresponding sulfonamides.

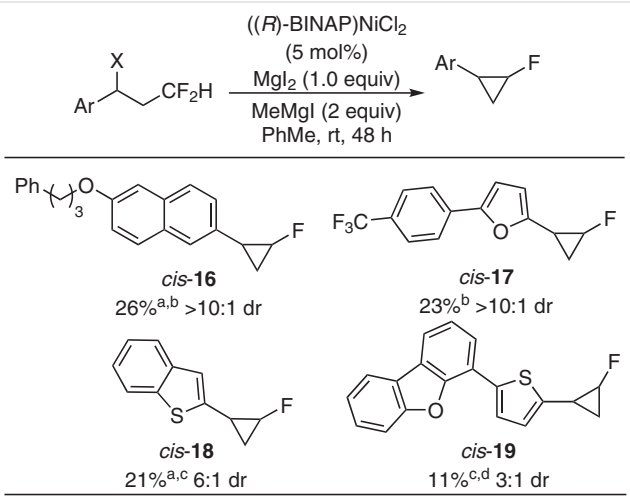

Scheme 5 Reaction scope. Yield is determined by ${ }^{1} \mathrm{H}$ NMR spectroscopy based on comparison to PhTMS as internal standard. ${ }^{\text {a }} 24$ h. ${ }^{b} \mathrm{X}=$ NTs. ${ }^{C} \mathrm{X}=$ OMe. ${ }^{\mathrm{d}}$ Yield based on recovered starting material.

Based on experimental and computational studies of related nickel-catalyzed XEC reactions, ${ }^{24,30}$ Scheme 6 shows a plausible catalytic cycle. After binding to the arene, the nickel catalyst first undergoes oxidative addition with the benzylic ether to generate benzylnickel species 22. Next, transmetallation between intermediate $\mathbf{2 2}$ and methylmagnesium iodide affords $\mathrm{Ni}(\mathrm{II})$ complex $\mathbf{2 5}$. The nucleophilic benzylnickel species then reacts with the alkyl fluoride in an intramolecular $S_{\mathrm{N}} 2$-type reaction, affording a 5:1 mixture of cis-6 and trans-6. Finally, the second equivalent of methylmagnesium iodide engages in transmetallation with $\mathrm{Ni}(\mathrm{II})$ species 26, which ultimately undergoes reductive elimination to release ethane. We were intrigued to observe that the nickel-catalyzed XEC reaction showed selectivity for cis-6 over trans-6 and hypothesized that cis-6 is thermodynamically more stable than trans- $\mathbf{6}$ due to stereoelectronic effects. To determine the relative stabilities, we calculated the energy of the two diastereomers in a density functional theory (DFT) study at the B3LYP level employing the $6-31 \mathrm{G}(\mathrm{d})$ basis set. ${ }^{31-33}$ The results of the DFT experiments demonstrated that cis-6 is thermodynamically more 


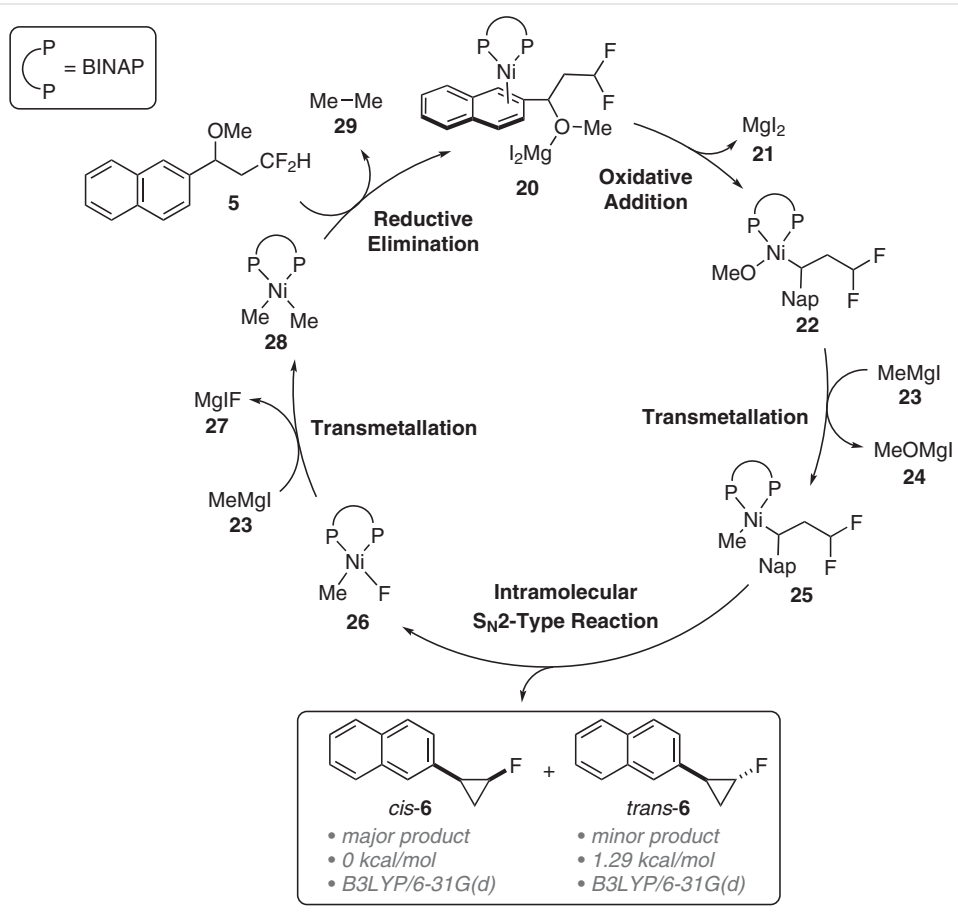

Scheme 6 Possible catalytic cycle

stable than trans- $\mathbf{6}$ by $1.29 \mathrm{kcal} / \mathrm{mol}$. Presumably, a stronger hyperconjugation interaction exists between $\sigma_{\mathrm{C}-\mathrm{H}}$ and $\sigma^{*}{ }_{\mathrm{C}-\mathrm{F}}$ in cis-6 when compared with the corresponding interaction between $\sigma_{\mathrm{C}-\mathrm{C}}$ and $\sigma^{*}{ }_{\mathrm{C}-\mathrm{F}}$ in trans-6. ${ }^{34}$ This stereochemical outcome is notable because it allows for the diastereoselective synthesis of disubstituted cyclopropanes.

In conclusion, we have developed a new approach for fluorinated cyclopropane synthesis. ${ }^{35}$ This strategy relies on emerging methods in photocatalytic olefin difluoromethylation coupled with an intramolecular nickel-catalyzed XEC reaction of the difluoromethyl group. Although our laboratory has previously established XEC reactions of alkyl fluorides, this work, to the best of our knowledge, represents the first example of an XEC reaction employing the difluoromethyl group as an electrophile. This advancement is particularly noteworthy due to the trend of $\mathrm{C}-\mathrm{F}$ bond strengths in fluorinated alkanes, where $-\mathrm{CF}_{3}>-\mathrm{CF}_{2} \mathrm{H}>-\mathrm{CFH}_{2}$. DFT calculations confirm the greater thermodynamic stability of the cis diastereomer relative to the trans diastereomer of the fluorinated cyclopropane product of the XEC reaction, consistent with the observed stereoselectivity. Ultimately, this newly established reactivity of low-valent nickel catalysts will aid in the future development of XC and $\mathrm{XEC}$ reactions of geminal dihalides and other sluggish electrophiles.

\section{Funding Information}

Financial support from the Center for Scientific Review (NIH NIGMS R01GM100212) is gratefully acknowledged.

\section{Acknowledgment}

Dr. Felix Grun is acknowledged for mass spectrometry data.

\section{Supporting Information}

Supporting information for this article is available online at https://doi.org/10.1055/s-0040-1706013.

\section{References and Notes}

(1) Present address: Department of Chemistry, The Scripps Research Institute, 10550 N Torrey Pines Road, La Jolla, CA 92037, USA.

(2) Present address: Department of Chemistry and Biochemistry, California State University, Los Angeles, CA 90032, USA.

(3) For reviews, see: (a) David, E.; Milanole, G.; Ivashkin, P.; CouveBonnaire, S.; Jubault, P.; Pannecoucke, X. Chem. Eur. J. 2012, 18, 14904. (b) Pons, A.; Poisson, T.; Pannecoucke, X.; Charette, A. B.; Jubault, P. Synthesis 2016, 48, 4060. (c) Dolbier, W. R.; Battiste, M. A. Chem. Rev. 2003, 103, 1071.

(4) Lemonnier, G.; Lion, C.; Quirion, J.-C.; Pin, J.-P.; Goudet, C.; Jubault, P. Bioorg. Med. Chem. 2012, 20, 4716.

(5) Taele, T. T. J. Med. Chem. 2016, 59, 8712. 
(6) For selected examples of fluorinated cyclopropane synthesis, see: (a) Meyer, O. G. J.; Fröhlich, R.; Haufe, G. Synthesis 2000, 1479. (b) Navuluri, C.; Charette, A. B. Org. Lett. 2015, 17, 4288. (c) Pons, A.; Ivashkin, P.; Poisson, T.; Charette, A. B.; Pannecoucke, X.; Jubault, P. Chem. Eur. J. 2016, 22, 6239. (d) Fang, F.; Cordes, D. B.; Slawin, A. M. Z.; O'Hagan, D. Chem. Commun. 2019, 55, 10539. (e) Delion, L.; Poisson, T.; Jubault, P.; Pannecoucke, X.; Charette, A. B. Can. J. Chem. 2020, 98, 516. (f) Kazia, A.; Melngaile, R.; Mishnew, A.; Veliks, J. Org. Biomol. Chem. 2020, 18, 1384.

(7) For recent reviews of photochemical difluoromethylation reactions, see: (a) Koike, T.; Akita, M. Org. Biomol. Chem. 2019, 17, 5413. (b) Pan, X.; Xia, H.; Wu, J. Org. Chem. Front. 2016, 3, 1163.

(8) Erickson, L. W.; Lucas, E. L.; Tollefson, E. J.; Jarvo, E. R. J. Am. Chem. Soc. 2016, 138, 14006.

(9) O'Hagan, D. Chem. Soc. Rev. 2008, 37, 308.

(10) Caron, S. Org. Process Res. Dev. 2020, 24, 470.

(11) (a) Ran, Y.; Lin, Q.-Y.; Xu, X.-H.; Qing, F.-L.J. Org. Chem. 2016, 81, 7001. (b) Arai, Y.; Tomita, R.; Ando, G.; Koike, T.; Akita, M. Chem. Eur. J. 2016, 22, 1262. (c) Noto, N.; Koike, T.; Akita, M. ACS Catal. 2019, 9, 4382.

(12) Noto, N.; Koike, T.; Akita, M.J. Org. Chem. 2016, 81, 7064.

(13) (a) Zhang, Z.; Tang, X.; Thomoson, C. S.; Dolbier, W. R. Org. Lett. 2015, 17, 3528. (b) Noto, N.; Koike, T.; Akita, M. Chem. Sci. 2017, 8, 6375. (c) Noto, N.; Tanaka, Y.; Koike, T.; Akita, M. ACS Catal. 2018, 8, 9408.

(14) (a) Cao, P.; Duan, J.-X.; Chen, Q.-Y.J. Chem. Soc., Chem. Commun. 1994, 737. (b) Thomoson, C. S.; Tang, X.-J.; Dolbier, W. R. J. Org. Chem. 2015, 80, 1264. (c) Tang, X. J.; Dolbier, W. R. Angew. Chem. Int. Ed. 2015, 54, 4246. (d) Lin, Q.-Y.; Ran, Y.; Xu, X.-H.; Qing, F.L. Org. Lett. 2016, 18, 2419.

(15) Yatham, V. R.; Shen, Y.; Martin, R. Angew. Chem. Int. Ed. 2017, 56, 10915.

(16) (a) Tang, X.-J.; Thomoson, C. S.; Dolbier, W. R. Org. Lett. 2014, 16, 4594. (b) Liu, J.; Zhuang, S.; Gui, Q.; Chen, X.; Yang, Z.; Tan, Z. Eur. J. Org. Chem. 2014, 3196. (c) He, Z.; Tan, P.; Ni, C.; Hu, J. Org. Lett. 2015, 17, 1838. (d) Zhang, Z.; Martinez, H.; Dolbier, W. R. J. Org. Chem. 2017, 82, 2589. (e) Zou, G.; Wang, X. Org. Biomol. Chem. 2017, 15, 8748. (f) Zhu, M.; You, Q.; Li, R. J. Fluorine Chem. 2019, 228, 109391.

(17) (a) Zhang, Z.; Tang, X.-J.; Dolbier, W. R. Org. Lett. 2016, 18, 1048. (b) Kim, Y. J.; Kim, D. Y. J. Fluorine Chem. 2018, 211, 119.

(18) Zhang, M.; Lin, J.-H.; Xiao, J.-C. Angew. Chem. Int. Ed. 2019, 58, 6079.

(19) (a) Tang, X.-J.; Zhang, Z.; Dolbier, W. R. Chem. Eur. J. 2015, 21, 18961. (b) Lin, Q.-Y.; Xu, X.-H.; Zhang, K.; Qing, F.-L. Angew. Chem. Int. Ed. 2016, 55, 1479. (c) Hu, W.-Q.; Xu, X.-H.; Qing, F.-L. J. Fluorine Chem. 2018, 208, 73.

(20) For reviews on photochemical difluoromethylation reactions, see refs. 7, 11, and: Koike, T.; Akita, M. Chem 2018, 4, 409.

(21) Zheng, J.; Cai, J.; Lin, J.; Guo, Y.; Xiao, J. Chem. Commun. 2013, 49, 7513.

(22) Deng, Z.; Lin, J.; Cai, J.; Xiao, J. Org. Lett. 2016, 18, 3206.
(23) Tamayo, A. B.; Alleyne, B. D.; Djurovich, P. I.; Lamansky, S.; Tsyba, I.; Ho, N. N.; Bau, R.; Thompson, M. E. J. Am. Chem. Soc. 2003, $125,7377$.

(24) Chen, P.-P.; Lucas, E. L.; Greene, M. A.; Zhang, S.-Q.; Tollefson, E. J.; Erickson, L. W.; Taylor, B. L. H.; Jarvo, E. R.; Hong, X. J. Am. Chem. Soc. 2019, 141, 5835.

(25) Schlenk, W.; Schlenk, W. Ber. Dtsch. Chem. Ges. B 1929, 62, 920.

(26) This principle has previously been successful in facilitating the oxidative addition of benzylic C-O bonds, see: (a) Greene, M. A.; Yonova, I. M.; Williams, F. J.; Jarvo, E. R. Org. Lett. 2012, 14, 4293. (b) Wisniewska, H. M.; Swift, E. C.; Jarvo, E. R. J. Am. Chem. Soc. 2013, 135, 9083.

(27) Liang, Z.; Xue, W.; Lin, K.; Gong, H. Org. Lett. 2014, 16, 5620.

(28) Knappke, C. E. I.; Grupe, S.; Gärtner, D.; Corpet, M.; Gosmini, C.; Jacobi von Wangelin, A. Chem. Eur. J. 2014, 20, 6828.

(29) Lucas, E. L.; Hewitt, K. A.; Chen, P.-P.; Castro, A. J.; Hong, X.; Jarvo, E. R. J. Org. Chem. 2019, 85, 1775.

(30) Xu, Z.; Yang, Y.; Jiang, J.; Fu, Y. Organometallics 2018, 37, 1114.

(31) Becke, A. D. J. Chem. Phys. 1993, 98, 5648.

(32) Lee, C.; Yang, W.; Parr, R. G. Phys. Rev. B. 1998, 37, 785.

(33) Hehre, W. J.; Radom, L.; Schleyer, P. v. R.; Pople, J. A. Ab Initio Molecular Orbital Theory; Wiley: New York, 1986.

(34) (a) Kirby, A. J. Stereoelectronic Effects; Compton, R. G.; Davies, S. G.; Evans, J.; Gladden, L. F., Ed.; Oxford University Press: New York, 1996. (b) Fleming, I. Molecular Orbitals and Organic Chemical Reactions, Student Edition; John Wiley \& Sons: Chichester, 2009.

(35) 2-(cis-2-Fluorocyclopropyl)naphthalene (cis-6) - Typical Procedure

In a glovebox, an oven-dried $7 \mathrm{~mL}$ vial equipped with a stir bar was charged with substrate 5 ( $24 \mathrm{mg}, 0.10 \mathrm{mmol}, 1.0$ equiv), $\mathrm{Ni}(\operatorname{cod})_{2}(1.4 \mathrm{mg}, 5.0 \mu \mathrm{mol}, 5.0 \mathrm{~mol} \%)$, rac-BINAP (3.1 mg, 5.0 $\mu \mathrm{mol}, 5.0 \mathrm{~mol} \%)$, and PhMe $(0.50 \mathrm{~mL}, 0.20 \mathrm{M}$ in substrate). $\operatorname{MeMgI}(77 \mu \mathrm{L}, 0.20 \mathrm{mmol}, 2.0$ equiv) was then added dropwise. After $24 \mathrm{~h}$, the reaction vial was removed from the glovebox, quenched with $\mathrm{MeOH}$, filtered through a plug of silica gel eluting with $\mathrm{Et}_{2} \mathrm{O}$, and concentrated in vacuo. Phenyltrimethylsilane (PhTMS; $8.6 \mu \mathrm{L}, 50 \mu \mathrm{mol}$ ) was added, and a ${ }^{1} \mathrm{H}$ NMR yield of $39 \%$ (5:1 dr, cis/trans) was obtained based on comparison to PhTMS as internal standard. The product was purified by column chromatography (100\% pentane) to yield the title compound as a white semisolid. An isolated yield was not reported due to volatility. The $\mathrm{dr}$ was determined based on the integration of the resonances in the ${ }^{1} \mathrm{H}$ NMR spectrum attributed to the hydrogens geminal to the fluorine atom. The relative configuration was assigned based on NOE analysis. TLC $R_{f}=0.6(2 \%$ $\mathrm{Et}_{2} \mathrm{O} /$ pentane). ${ }^{1} \mathrm{H}$ NMR $\left(500 \mathrm{MHz}, \mathrm{CDCl}_{3}\right): \delta=7.81-7.77(\mathrm{~m}, 3$ H), $7.71(\mathrm{~s}, 1 \mathrm{H}), 7.46-7.39(\mathrm{~m}, 3 \mathrm{H}), 4.85$ (dtd, $J=66.0,6.2,2.9$ $\mathrm{Hz}, 1 \mathrm{H}), 2.25-2.19(\mathrm{~m}, 1 \mathrm{H}), 1.43$ (dtd, $J=22.5,7.7,2.8 \mathrm{~Hz}, 1 \mathrm{H})$, 1.30-1.23 (m, $1 \mathrm{H}) .{ }^{13} \mathrm{C}$ NMR $\left(125.4 \mathrm{MHz}, \mathrm{CDCl}_{3}\right): \delta=133.7(\mathrm{~d}, J=$ $3.0 \mathrm{~Hz}), 133.5,132.4,127.8,127.73,127.68,127.23$ (d, $J=1.4$ $\mathrm{Hz}), 127.17(\mathrm{~d}, J=1.1 \mathrm{~Hz}), 126.1,125.5,72.7(\mathrm{~d}, J=221.9 \mathrm{~Hz})$, $21.8(\mathrm{~d}, J=11.1 \mathrm{~Hz}), 11.9(\mathrm{~d}, J=10.4 \mathrm{~Hz}) .{ }^{19} \mathrm{~F}$ NMR $(365.4 \mathrm{MHz}$, $\mathrm{CDCl}_{3}$ ): $\delta=-222.2$. HRMS (TOF MS ES + ): $\mathrm{m} / z[\mathrm{M}]^{+}$calcd for $\mathrm{C}_{13} \mathrm{FH}_{11}: 186.0845$; found: 186.0840 . 